\title{
Health Economics And Quality of Life Between Uncut Roux-En-Y And Roux-En- Y Reconstruction After Total Gastrectomy
}

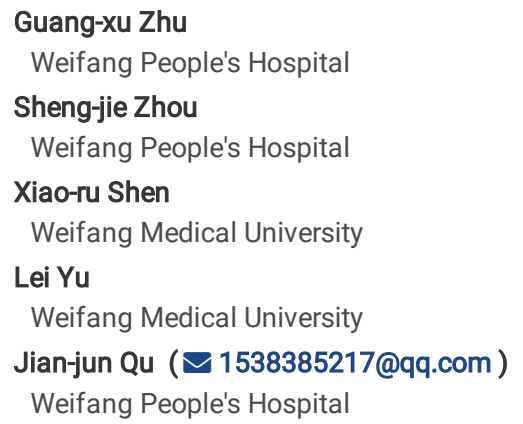

Keywords: Total gastrectomy, Uncut Roux-en-Y anastomosis, Roux-en-Y anastomosis, Health economics, Quality of life

Posted Date: February 3rd, 2022

DOI: https://doi.org/10.21203/rs.3.rs-1299683/v1

License: (c) (7) This work is licensed under a Creative Commons Attribution 4.0 International License. Read Full License 


\section{Abstract}

Purpose: This study aims to compare the health economics and quality of life between uncut Roux-en-Y and Roux-en-Y reconstruction after laparoscopicassisted total gastrectomy.

Methods: Between January 2016 and January 2019, 164 patients underwent laparoscopic-assisted total gastrectomy (uncut Roux-en-Y reconstruction, $n=71$; Roux-en-Y, $n=93)$. The patients' data were collected and reviewed retrospectively.

Results: The perioperative index, operating time, digestive tract reconstruction time, and first postoperative exhaust time of the U-RY group were shorter than those of the RY group $(P<0.05)$. Differences in the quality of life $(Q \circ L)$ index 12 months postoperation were not significantly different between the groups $(P>$ 0.05). No recanalization was found in the U-RY obliterated afferent jejunal limb. The cost of mechanical staples and

average hospitalization in the U-RY group were significantly lower than that in the RY group $(P<0.05)$.

Conclusion: The postoperative health economics of U-RY reconstruction may be superior to those of RY reconstruction after laparoscopic-assisted total gastrectomy. The QoL of the U-RY group is similar to that of the RY group.

\section{Introduction}

As living standards improve and dietary structures change, the incidence of malignant tumors in the middle and upper portions of the stomach and esophagogastric junction has gradually increased year by year. At present, surgical resection remains the main treatment for gastric cancer. ${ }^{1-2}$ Developments in laparoscopic techniques, postoperative adjuvant chemotherapy, and targeted therapy since the 21 st century have resulted in vast improvements in the overall quality of life (QoL) of patients with gastric cancer after surgery. In many cases, QoL is a major consideration in the treatment plan of surgeons. ${ }^{3}$

Although U-RY and RY reconstruction after laparoscopic-assisted total gastrectomy is widely adopted, each technique presents unique advantages and disadvantages. RY anastomosis preserves good anti-bile and pancreatic reflux ability, but some patients reported Roux-Y stasis syndrome after gastrectomy. In theory, U-RY anastomosis results in strong anti-biliary, pancreatic juice regurgitation, and RSS capabilities; however, the possibility of dehiscence and recanalization of the jejunal occlusion cannot be exlucded..$^{4-5}$ Although some studies have compared the safety, feasibility, and nutritional status of U-RY and RY anastomoses, ${ }^{6-10}$ research on the health economics and QoL of laparoscope-assisted U-RY and RY reconstruction after total gastrectomy is limited. Today, experts at home and abroad continue to debate the advantages and disadvantages of U-RY anastomosis after surgical resection. In addition, no study that dynamically compares the QoL of U-RY with RY reconstruction by using standard questionnaires at multiple time points has yet been published.

Herein, we performed a retrospective study to compare the results of U-RY and RY reconstruction after laparoscopic-assisted total gastrectomy for gastric cancer in China. Specifically, we report the results of interim analysis over a period of 12 months.

\section{Materials And Methods}

\section{Patients}

The study was conducted in accordance with the Declaration of Helsinki (as revised in 2013). This study was approved by the Ethics Committee of Weifang People's Hospital . All patients consented to the data being used for research when receiving treatment. The inclusion criteria were as follows: gastroscopic biopsy-confirmed adenocarcinoma of the stomach, imaging confirmation that the tumor is located in the middle and upper portions of the stomach or esophagogastric junction, and CTNM stage - . The exclusion criteria were as follows: received neoadjuvant radiotherapy and chemotherapy prior to operation, failure to achieve $\mathrm{R} 0$ resection, and gastric stump cancer.

The study protocol was approved by the research ethics committee of Weifang People's Hospital. Written informed consent was obtained from all patients prior to operation.

\section{Operative Procedure}

All patients underwent laparoscopic-assisted total gastrectomy with D2 lymphadenectomy on the basis of Japanese gastric cancer treatment guidelines. ${ }^{11}$ After laparoscopic lymph node dissection, a small (i.e., approximately $10 \mathrm{~cm}$ ) incision was made from the upper abdomen, the esophagus was cut off at approximately $2-5 \mathrm{~cm}$ from the upper edge of the lesion, and the specimen was removed. Digestive tract reconstruction was performed in vitro.

U-RY and RY reconstructions were established by using mechanical staples. In the U-RY group, an esophagojejunostomy was established between the lower esophagus and jejunum $45 \mathrm{~cm}$ distal to the ligament of Treitz after total gastrectomy. Then, a side-to-side jejunojejunostomy was established between the afferent and efferent jejunal limbs approximately $40 \mathrm{~cm}$ distal to the esophagojejunostomy site and $20 \mathrm{~cm}$ distal to the ligament of Treitz. Finally, the jejunal lumen was occluded using the four-row (knifeless) stapler method at a site $3-5 \mathrm{~cm}$ proximal to the esophagojejunostomy. In the R-Y group,

the jejunum was divided and closed using a $60 \mathrm{~mm}$ linear $20 \mathrm{~cm}$ distant from the Treitz ligament. Next, an esophagojejunostomy was established between the lower esophagus and distal jejunum with a $25 \mathrm{~mm}$ circular stapler in an end-to-side fashion. A side-to-side jejunojejunostomy was established between the proximal and distal jejunums $40 \mathrm{~cm}$ below the esophagojejunostomy.

All operations on patients with gastric cancer were performed by the same surgical team. The two methods of digestive tract reconstruction are depicted in Figs. 1,2,3. 


\section{Observation indicators and evaluation standards}

The operation time, digestive tract reconstruction time, intraoperative blood loss, first exhaust time, postoperative hospital stay, and perioperative complications were monitored during the perioperative period.

Average hospitalization and mechanical staple costs were also recorded as health economics.

The QoL index of the two groups 1 year after operation was assessed using the European Organization for Research and Treatment of Cancer (EORTC) QLQC30 and QLQ-STO22 questionnaires. ${ }^{12}$ Gastroscopy and upper gastrointestinal angiography were reviewed 1 year after surgery, and recanalization of the jejunal occlusion in the U-RY group, if any, was recorded.

The EORTC QLQ-C30 (V3.0) questionnaire is 30-item scale for cancer patients. Except for items 29 and 30, the scores for which ranged from 1 to 7 , all other items were scored from 1 to 4, corresponding to the response categories "never," " a little," "quite a bit," and "very much." The 30 items could be divided into 15 fields, including five functional fields (i.e., physical, role, cognitive, emotional, and social), three symptom fields (i.e., pain, fatigue, nausea and vomiting), one global health status field, and six single items(each as a field, i.e., Appetite loss, Insomnia, Constipation, Dyspnea, Diarrhea, Financial difficulties). ${ }^{13}$ The EORTC QLQ-STO22 questionnaire consists of 22 items that can be divided into 9 areas: five symptom areas (i.e., dysphagia, pain, eating restrictions, reflux symptoms, and anxiety) and four single items (i.e., dry mouth, taste, body image, and hair loss). ${ }^{14}$ The QLQ-C30 and QLQ-STO22 responses were linearly transformed into scores ranging from 0 to 100 according to the EORTC scoring manual. High scores for items related to global health status and functions and low scores for items related to symptoms and ten single items (i.e., Appetite loss, Insomnia, Constipation, Dyspnea, Diarrhea, Financial difficulties, dry mouth, taste, body image, and hair loss) denote a favorable QoL. The baseline QoL was obtained prior to the operations. Postoperative QoL scores were collected 1, 6, and 12 months after the operation by telephone calls, letters, or outpatient visits. The follow-up period was up to January 2020.

\section{Statistical analysis}

SPSS version 25.0 software (SPSS, Chicago, IL, USA) was used for statistical analysis. Continuous variables were compared using independent-samples $t$ test and are expressed as mean \pm standard deviation. The frequencies of categorical variables are expressed as rates, and rates were compared using the chisquared or Fisher's exact test. Here, $\mathrm{P}<0.05$ was considered statistically significant.

\section{Results}

\section{Patient characteristics}

A total of 176 patients were included in this work on the basis of the inclusion and exclusion criteria described above. Seven patients were lost to follow-up and five died (i.e., two patients in the U-RY group and three patients in the RY group). Finally, 164 patients (male $=135,82.3 \%$; female $=29,17.7 \%$ ) were included in this study. These patients were divided into the U-RY $(n=71)$ and RY $(n=93)$ groups according to the technique used for digestive tract reconstruction. The baseline characteristics of the two groups were comparable (Table 1).

Table 1. Clinicopathological characteristics of patients in the two groups 


\begin{tabular}{|c|c|c|c|}
\hline Characteristic & U-RY group $n=71$ & $\begin{array}{l}\text { RY group } \\
n=93\end{array}$ & $P$ value \\
\hline Age (years) & $61.6 \pm 8.3$ & $59.7 \pm 7.9$ & 0.136 \\
\hline Sex $\%$ & & & 0.854 \\
\hline Male & 5881.7 & 7782.8 & \\
\hline female & 1318.3 & 1617.2 & \\
\hline $\mathrm{BMI}(\mathrm{kg} / \mathrm{m} 2)$ & & & 0.348 \\
\hline$<18.5$ thin & 2 & 0 & \\
\hline $18.5 \sim 25$ normal & 47 & 58 & \\
\hline 25 30 overweight & 20 & 31 & \\
\hline$\geq 30$ obesity & 2 & 4 & \\
\hline c TNM stage (AJCC 7th) & & & 0.692 \\
\hline & 10 & 15 & \\
\hline & 61 & 78 & \\
\hline Histologic Type \% & & & 0.877 \\
\hline Poor & 46 & 60 & \\
\hline Moderate & 23 & 29 & \\
\hline Well & 2 & 4 & \\
\hline Tumor size \% & & & 0.998 \\
\hline$<4 \mathrm{~cm}$ & 2940.8 & 3335.5 & \\
\hline$\geq 4 \mathrm{~cm}$ & 4259.2 & 6064.5 & \\
\hline
\end{tabular}

\section{Perioperative condition and health economics}

No deaths were recorded during the perioperative period. The operation, digestive tract reconstruction, and first postoperative exhaust times of the U-RY group were shorter than those of the RY group $(\mathrm{P}<0.05)$. The rates of incidence of specific complications in the two groups were $12.7 \%$ and $16.1 \%$, respectively, but the difference observed was not statistically significant. All perioperative complications were cured by conservative treatment, and no case of secondary operation was noted. The cost of mechanical staples and average hospitalization in the U-RY group were significantly lower than that in the RY group $(\mathrm{P}<$ 0.05; Table 2).

Table 2. Perioperative conditions and health economics

\begin{tabular}{|llll|}
\hline Item & U-RY group $n=71$ & RY group $n=93$ & $P$ value \\
\hline Operative time min & $252.7 \pm 21.1$ & $261.5 \pm 20.5$ & 0.008 \\
\hline Time to digestive tract reconstruction min & $33.4 \pm 6.5$ & $40.5 \pm 6.9$ & 0.000 \\
\hline Blood loss $\mathrm{ml}$ & $62.7 \pm 9.6$ & $65.4 \pm 9.3$ & 0.066 \\
\hline Digestive tract reconstruction time hours & $56.2 \pm 7.7$ & $59.5 \pm 8.5$ & 0.010 \\
\hline Postoperative hospital stay days & $10.9 \pm 1.8$ & $11.4 \pm 1.8$ & 0.053 \\
\hline Postoperative complications \% & 912.7 & $15(16.1)$ & 0.535 \\
\hline Bleeding & 1 & 1 & \\
\hline Infection & 7 & 13 & \\
\hline Anastomosis leakage & 1 & 0 & 0.007 \\
\hline Intestinal obstruction & 0 & 1 & 0.000 \\
\hline Hospitalization costs (wan yuan) & $5.5 \pm 0.6$ & $5.8 \pm 0.7$ & \\
\hline The mechanical staplers cost wan yuan & $1.5 \pm 0.2$ & $1.8 \pm 0.2$ & \\
\hline sutures, circular stapler, linear staplers & & & \\
\hline
\end{tabular}

QoL assessment 
Twelve months postoperation, the main symptoms of the patients included postprandial abdominal pain and discomfort, sulks, and reflux. No significant difference in QoL was noted between the two groups at baseline and various time points after surgery $(P>0.05)$.

QLQ-C30 scale: The scores of physical functioning, role functioning (Whether limited in doing work, other daily activities, pursuing hobbies and other leisure time activities), social functioning, and global health status increased whereas the scores of pain and fatigue decreased in both groups. The pain scores of the two groups were relatively high from 1 month to 12 months postoperation.

QLQ-STO22 scale: From 1 month to 12 months after surgery, symptoms such as dysphagia, reflux, Pain and restricted eating significantly improved. At 6 months postoperation, the hair loss and taste scores of the two groups remained relatively high. The scores of reflux symptoms 12 months after RY anastomosis were lower than those observed after U-RY, but the difference between groups was not significant $(P>0.05)$. No significant improved in other symptoms, such as dry mouth, changes in taste, anxiety, body image, and hair loss, were found ( Fig. 4,Table 3 ).

Table 3 The preoperative and postoperative QoL items scores of patients between the two groups 


\begin{tabular}{|c|c|c|c|c|c|c|c|c|c|c|c|c|}
\hline & \multicolumn{3}{|c|}{ Preoperative } & \multicolumn{3}{|c|}{ Postoperative $1 \mathrm{M}$} & \multicolumn{3}{|c|}{ Postoperative $6 \mathrm{M}$} & \multicolumn{3}{|c|}{ Postoperative $12 \mathrm{M}$} \\
\hline & U-RY & RY & $\mathrm{P}$ & U-RY & RY & $\mathrm{P}$ & U-RY & RY & $\mathrm{P}$ & U-RY & RY & $\mathrm{P}$ \\
\hline \multicolumn{13}{|l|}{$\begin{array}{l}\text { EORTC QLQ } \\
\text { C-30 }\end{array}$} \\
\hline $\begin{array}{l}\text { Physical } \\
\text { functioning }\end{array}$ & $95.4 \pm 4.1$ & $96.3 \pm 4.4$ & 0.173 & $79.3 \pm 4.3$ & $78.2 \pm 5.0$ & 0.146 & $88.1 \pm 4.8$ & $87.7 \pm 4.6$ & 0.567 & $93.4 \pm 3.4$ & $93.6 \pm 3.9$ & $0.80^{\circ}$ \\
\hline $\begin{array}{l}\text { Role } \\
\text { functioning }\end{array}$ & $92.8 \pm 3.5$ & $93.7 \pm 3.7$ & 0.109 & $68.3 \pm 4.4$ & $70.2 \pm 9.7$ & 0.121 & $86.7 \pm 4.8$ & $87.8 \pm 4.1$ & 0.129 & $95.1 \pm 4.3$ & $94.2 \pm 3.8$ & $0.15 t$ \\
\hline $\begin{array}{l}\text { Cognitive } \\
\text { functioning }\end{array}$ & $90.1 \pm 5.9$ & $89.6 \pm 5.4$ & 0.580 & $86.2 \pm 6.2$ & $84.5 \pm 5.7$ & 0.085 & $92.7 \pm 6.4$ & $94.1 \pm 5.1$ & 0.133 & $96.0 \pm 4.1$ & $95.0 \pm 4.7$ & $0.14 t$ \\
\hline $\begin{array}{l}\text { Emotional } \\
\text { functioning }\end{array}$ & $83.1 \pm 5.2$ & $81.4 \pm 6.3$ & 0.064 & $91.4 \pm 3.9$ & $90.1 \pm 6.1$ & 0.099 & $95.6 \pm 4.3$ & $94.6 \pm 5.0$ & 0.162 & $95.9 \pm 3.7$ & $96.1 \pm 3.6$ & 0.64 \\
\hline $\begin{array}{l}\text { Social } \\
\text { functioning }\end{array}$ & $89.3 \pm 6.4$ & $87.4 \pm 6.7$ & 0.074 & $78.1 \pm 6.2$ & $79.4 \pm 6.7$ & 0.219 & $85.3 \pm 7.9$ & $83.2 \pm 6.7$ & 0.077 & $97.1 \pm 4.7$ & $96.1 \pm 4.1$ & 0.11 ! \\
\hline $\begin{array}{l}\text { Global } \\
\text { Health } \\
\text { status }\end{array}$ & $86.3 \pm 9.7$ & $88.7 \pm 8.1$ & 0.088 & $68.5 \pm 8.8$ & $66.2 \pm 8.6$ & 0.089 & $81.1 \pm 8.6$ & $82.2 \pm 10.7$ & 0.497 & $85.9 \pm 9.4$ & $87.6 \pm 6.7$ & $0.16:$ \\
\hline Pain & $13.2 \pm 10.7$ & $11.0 \pm 9.8$ & 0.177 & $30.7 \pm 10.8$ & $29.1 \pm 11.4$ & 0.358 & $21.4 \pm 11.8$ & $18.4 \pm 11.6$ & 0.102 & $15.4 \pm 10.3$ & $13.0 \pm 7.7$ & 0.08 ! \\
\hline Fatigue & $12.6 \pm 7.3$ & $11.7 \pm 8.7$ & 0.487 & $26.6 \pm 8.1$ & $25.7 \pm 8.7$ & 0.489 & $10.6 \pm 9.9$ & $9.6 \pm 9.2$ & 0.507 & $8.3 \pm 6.2$ & $9.3 \pm 7.9$ & 0.38 ! \\
\hline $\begin{array}{l}\text { Nausea and } \\
\text { vomiting }\end{array}$ & $7.9 \pm 7.3$ & $7.3 \pm 7.3$ & 0.571 & $12.9 \pm 9.6$ & $15.6 \pm 9.0$ & 0.067 & $6.7 \pm 7.3$ & $7.2 \pm 6.3$ & 0.618 & $6.0 \pm 6.1$ & $7.8 \pm 6.8$ & $0.07:$ \\
\hline Insomnia & $20.6 \pm 11.1$ & $19.3 \pm 14.1$ & 0.515 & $9.6 \pm 9.6$ & $11.1 \pm 9.7$ & 0.338 & $6.2 \pm 8.4$ & $7.9 \pm 9.5$ & 0.216 & $6.0 \pm 6.9$ & $6.8 \pm 6.5$ & $0.41^{\circ}$ \\
\hline $\begin{array}{l}\text { Appetite } \\
\text { loss }\end{array}$ & $9.7 \pm 8.9$ & $8.7 \pm 8.2$ & 0.478 & $14.3 \pm 10.8$ & $13.3 \pm 11.8$ & 0.588 & $7.1 \pm 7.4$ & $8.2 \pm 7.0$ & 0.331 & $5.6 \pm 6.9$ & $7.7 \pm 6.7$ & $0.05^{\circ}$ \\
\hline Constipation & $5.3 \pm 5.9$ & $5.8 \pm 6.5$ & 0.601 & $8.4 \pm 6.9$ & $9.6 \pm 7.8$ & 0.295 & $5.9 \pm 5.3$ & $6.6 \pm 6.6$ & 0.495 & $4.2 \pm 4.7$ & $4.4 \pm 4.8$ & 0.77\{ \\
\hline Diarrhea & $5.6 \pm 5.9$ & $5.9 \pm 7.1$ & 0.725 & $12.9 \pm 11.0$ & $14.4 \pm 10.2$ & 0.372 & $5.7 \pm 6.4$ & $7.7 \pm 7.2$ & 0.063 & $4.9 \pm 4.8$ & $6.6 \pm 6.6$ & 0.06 \\
\hline Dyspnea & $3.7 \pm 4.3$ & $4.5 \pm 5.9$ & 0.343 & $13.6 \pm 11.2$ & $14.3 \pm 12.4$ & 0.705 & $5.6 \pm 5.5$ & $6.3 \pm 5.9$ & 0.401 & $4.1 \pm 4.6$ & $4.8 \pm 4.4$ & $0.36 !$ \\
\hline $\begin{array}{l}\text { Financial } \\
\text { difficulties }\end{array}$ & $26.2 \pm 17.0$ & $24.3 \pm 16.9$ & 0.499 & $14.9 \pm 15.7$ & $13.7 \pm 14.5$ & 0.635 & $9.8 \pm 13.5$ & $11.7 \pm 10.3$ & 0.315 & $8.2 \pm 8.9$ & $9.2 \pm 8.5$ & $0.45 t$ \\
\hline \multicolumn{13}{|l|}{$\begin{array}{l}\text { EORTC QLQ } \\
\text { STO-22 }\end{array}$} \\
\hline Dysphagia & $13.8 \pm 14.2$ & $12.3 \pm 12.2$ & 0.467 & $19.5 \pm 14.2$ & $21.1 \pm 13.2$ & 0.476 & $9.2 \pm 10.8$ & $8.5 \pm 10.8$ & 0.678 & $8.8 \pm 11.4$ & $6.5 \pm 9.3$ & 0.161 \\
\hline Pain & $16.2 \pm 10.1$ & $18.1 \pm 9.1$ & 0.191 & $28.7 \pm 14.0$ & $27.2 \pm 12.3$ & 0.482 & $13.4 \pm 9.7$ & $10.9 \pm 9.8$ & 0.097 & $11.3 \pm 13.5$ & $8.7 \pm 8.4$ & $0.12 i$ \\
\hline $\begin{array}{l}\text { Reflux } \\
\text { symptom }\end{array}$ & $6.5 \pm 6.5$ & $7.9 \pm 8.2$ & 0.235 & $19.2 \pm 8.4$ & $16.1 \pm 10.9$ & 0.055 & $11.4 \pm 14.0$ & $8.9 \pm 9.8$ & 0.188 & $10.7 \pm 9.4$ & $8.3 \pm 8.7$ & 0.08 ! \\
\hline $\begin{array}{l}\text { Eating } \\
\text { restrictions }\end{array}$ & $11.8 \pm 10.5$ & $10.5 \pm 10.3$ & 0.421 & $24.4 \pm 11.7$ & $23.4 \pm 12.4$ & 0.617 & $11.0 \pm 9.2$ & $12.5 \pm 10.5$ & 0.333 & $9.9 \pm 10.6$ & $11.2 \pm 10.4$ & 0.44 ! \\
\hline $\begin{array}{l}\text { Having a dry } \\
\text { mouth }\end{array}$ & $8.3 \pm 8.8$ & $8.9 \pm 9.0$ & 0.661 & $13.3 \pm 9.8$ & $14.9 \pm 9.8$ & 0.316 & $8.9 \pm 9.1$ & $9.1 \pm 10.4$ & 0.875 & $6.2 \pm 7.2$ & $8.4 \pm 8.4$ & 0.07 ? \\
\hline Taste & $8.0 \pm 6.8$ & $6.9 \pm 6.2$ & 0.295 & $5.6 \pm 5.8$ & $6.4 \pm 6.3$ & 0.446 & $10.1 \pm 7.9$ & $12.1 \pm 9.2$ & 0.140 & $4.8 \pm 5.9$ & $5.7 \pm 5.2$ & $0.34 !$ \\
\hline Anxiety & $18.5 \pm 10.7$ & $17.1 \pm 13.5$ & 0.468 & $12.7 \pm 12.3$ & $14.5 \pm 14.1$ & 0.374 & $7.5 \pm 8.7$ & $8.4 \pm 8.8$ & 0.542 & $8.0 \pm 8.2$ & $9.1 \pm 9.2$ & $0.42:$ \\
\hline Body image & $7.3 \pm 7.2$ & $8.7 \pm 8.1$ & 0.259 & $14.1 \pm 8.3$ & $13.0 \pm 9.3$ & 0.423 & $7.6 \pm 7.2$ & $7.2 \pm 7.9$ & 0.748 & $5.3 \pm 6.3$ & $5.5 \pm 5.9$ & $0.87:$ \\
\hline Hair loss & $4.8 \pm 5.0$ & $5.4 \pm 6.1$ & 0.523 & $4.8 \pm 4.9$ & $3.2 \pm 5.8$ & 0.073 & $16.2 \pm 11.0$ & $15.3 \pm 8.2$ & 0.535 & $4.3 \pm 4.6$ & $3.9 \pm 5.2$ & $0.59:$ \\
\hline
\end{tabular}

\section{Discussion}

Some controversy exists regarding the application of U-RY anastomosis to digestive tract reconstruction after laparoscopic-assisted total gastrectomy. In particular, two main aspects are debated: (1) In terms of surgical safety and feasibility, the length of the mesentery may be too short, which could result in excessive tension of the esophagojejunostomy and increased incidence of anastomotic leakage during U-RY reconstruction. Moreover, when the tumor is located at the gastroesophageal junction, the anastomotic site of the esophagojejunostomy tends to be at a higher position ("at a high position" relative to esophagogastric junction). Thus, the afferent and efferent jejunal limbs may be embedded in the esophageal hiatus, and mechanical intestinal obstruction may develop. (2) The possibility of dehiscence and recanalization of the jejunal occlusion cannot be excluded, and severe reflux esophagitis may occur after recanalization. ${ }^{15-17}$ 
Uncut Roux-en-Y anastomosis is widely used in gastrointestinal reconstruction procedure after radical gastrectomy for gastric cancer. However, the proximal jejunal closure point recanalization of the input loop is an important complication of postoperative patients with prolonged time, resulting in pancreatic juice or bile reflux, which can lead to inflammatory lesions of the remnant stomach or esophagus. Poor selection of the location of the closure point during anastomosis causes a large amount of food deposited in the blind loop to be pushed and impacted, resulting in loosened threads or failed U-shaped staples, which may cause recanalization complications. Most scholars believe that the shortening of the jejunal tube closure point to the optimal position of 2 to $3 \mathrm{~cm}$ from the residual gastrojejunostomy can significantly reduce food retention, decrease the pressure of the closure point and the incidence of recanalization. ${ }^{18}$ At present, the application of new anastomotic techniques and materials such as four row and six-row U-shaped staples and 7\# wire ligation under laparoscopy can prevent the occurrence of recanalization of the closure point. Uncut Roux-en-Y anastomosis is safe and has few complications, and is expected to become one of the best ways of digestive tract reconstruction. ${ }^{18}$

\section{In terms of perioperative conditions}

This study found that the incidence of short-term complications in the U-RY group is similar to that in the traditional $R Y$ group $(P>0.05)$. During digestive tract reconstruction in the U-RY group, a small number of patients with obesity and too high severed esophagus (approximately $5 \mathrm{~cm}$ ) exhibited mesenteric tension ("too high severed esophagus" relative to esophagogastric junction). We performed mesentery incision and release and cut open part of the diaphragm to enlarge the space of the diaphragm hiatus and solve problems related to the safety and feasibility of the operation. The operation, digestive tract reconstruction, and first postoperative exhaust times of the U-RY group were shorter than those of the RY group $(P<0.05)$. A retrospective study found that the digestive tract reconstruction time of the U-RY group is 5 min shorter than that of the RY group, but the overall morbidity was not significantly different between groups $(P<0.05) .{ }^{6}$ Because U-RY reduces the operation times for intestinal tract dissection and mesangial cutting, it may shorten the overall operation and digestive tract reconstruction times. U-RY also maintains the continuity and integrity of the intestinal tube such that the intestinal function of patients is quickly recovered after operation. ${ }^{19-20}$ These results are similar to those of Yun et al. ${ }^{21}$

\section{In terms of quality of life}

The QLQ-C30 and QLQ-ST022 questionnaires are important scales for measuring the QoL of cancer patients; indeed, both are often used to evaluate the QoL of postoperative patients with gastric cancer. ${ }^{14,22-24}$ This study found that the physical function, role functioning, and global health status of the patients were improved and their pain symptoms were alleviated within 1-12 months after operation. This result suggests that resection of gastric tumor can improve the QoL of patients. Preoperative insomnia, anxiety, and emotional scores were generally high, likely because of the psychological factors of patients. Earlier studies indicated that U-RY reconstruction preserves strong anti-biliary, pancreatic juice regurgitation capabilities and improves the QoL of patients after surgery. ${ }^{4,25}$ In this study, although no significant difference in the incidence of reflux esophagitis was noted between the two groups $(P>0.05)$, the reflux symptom score of the U-RY group was significantly higher than that of the RY group. The differences found may be caused by differences in the operation steps, abdominal incision, and operative visual field and the establishment of a jejunal closure point of input loop in the U-RY group (Figs 2). The length of the jejunal blind loop in the U-RY group was longer than that in the RY group, and a long blind loop could allow intestinal fluid accumulation in the blind loop in the former, thereby increasing the incidence of alkaline reflux esophagitis. Whether the length of the jejunal blind loop is closely related to the incidence of reflux esophagitis requires further study.

Pain is a subjective feeling that is generally believed to be affected by postoperative abdominal adhesion, reflux symptoms, and other factors. ${ }^{12}$ Both groups reported high pain scores 12 months after surgery, and the difference between groups was not statistically significant $(P>0.05)$. The main manifestations of pain include postprandial abdominal pain and discomfort, most of which could be relieved after $30 \mathrm{~min}$. We believe that this pain may be attributed to patients eating large amounts of food within a short period of time, which results in forced expansion of the efferent jejunal limbs and tractive pain; as food is digested, the small intestine is weakened by traction stimulation. Abdominal pain and discomfort symptoms were gradually relieved. Six months postoperation, the hair loss and taste scores of the two groups remained relatively high, mainly because the patient was likely to be on postoperative adjuvant chemotherapy. The jejunal lumen is occluded using the four-row (knifeless) stapler method at a site located 3-5 cm proximal to the esophagojejunostomy. We did not observe recanalization of the jejunal occlusion in the U-RY reconstruction 12 months postoperation.

\section{In terms of health economics}

The cost of mechanical staples and average hospitalization in the U-RY group were significantly lower than that in the RY group $(P<0.05)$. One of the main considerations in U-RY reconstruction is the reduction in the number of mechanical staples and sutures used during the operation, which can help reduce the operation cost to a certain extent and reduce the economic burden of patients.

This study includes certain limitations that must be considered when interpreting the results. First, the present work is a single-center retrospective study including a small number of cases and short follow-up time. Thus, medical evidence supporting our conclusions is lacking. The results of the present study must be further verified by a large multi-center randomized controlled trial. Secondly, the data of the QLQ-C30 and QLQ-STO22 scales were obtained through questionnaire surveys, which means the results may be susceptible to a certain degree of bias due to the patients' emotions, feelings, cultural background, and educational level.

\section{Conclusion}

The postoperative health economics of U-RY reconstruction may be superior to those of RY reconstruction after laparoscopic-assisted total gastrectomy. The QoL of the U-RY group was comparable with that of the RY group. 


\section{Declarations}

Ethics approval and consent to participate

This study was conducted in accordance with the declaration of Helsinki. This protocol of the study had been approved by the Ethics Committee of the Weifang People's Hospital.Written informed consent was obtained from each patient in this study.

\section{Consent for publication}

The authors agree to publish. A consent written by patient's guardians as to the agreement to publish the patient's clinical details and images in this study have been obtained prior to the study.

\section{Availability of data and materials}

All data generated or analysed during this study are included in this published article.

\section{Competing interests}

The authors declare that they have no competing interests.

\section{Funding}

Funding program:Weifang Science and Technology Development Plan Project (2019YX002); Shandong Province Medical and Health Science and Technology Development Plan (Project No. 2017WSA07019);

\section{Contributions}

Jian-jun Qu and Xiao-ru Shen conjectured the study and reviewed the paper; Guang-xu Zhu and Sheng-jie Zhou analyzed the data and wrote the draft; Lei Yu selected the patients and collected the data.

\section{Acknowledgements}

This work was completely supported by Weifang People's Hospital.

\section{Author information}

Guang-xu Zhu and Sheng-jie Zhou contributed equally to this work

Affiliations

Department of General surgery, Weifang People's Hospital, Shandong Weifang, China

Guang-xu Zhu, Jian-jun Qu

Department of Anesthesiology, Weifang People's Hospital, Shandong Weifang, China

Sheng-jie Zhou

Weifang Medical University, Shandong Weifang, China

Xiao-ru Shen, Lei Yu

\section{References}

1. Li XP, Hui QY. Epidemiologic research progress of pathogenic site changes of gastric cancer. Chin Med Herald. 2014; 11(17):160-2.

2. Song HM, Zhou JF, Wang JX, He QL. The application of laparoscopic-assisted proximal gastrectomy and double-tract anastomosis in the treatment of early proximal gastric cancer. Chin J Gen Surg. 2019; 3410 891-93.

3. Orditura M, Galizia G, Sforza V, Gambardella V, Fabozzi A, Laterza MM, et al. Treatment of gastric cancer. World J Gastroenterol. 2014; 20(7):1635-49.

4. Yang D, He L, Tong WH, Jia ZF, Su TR, Wang Q. Randomized controlled trial of uncut Roux-en-Y vs Billroth reconstruction after distal gastrectomy for gastric cancer: Which technique is better for avoiding biliary reflux and gastritis?. World J Gastroenterol.2017;23(34):6350-56.

5. Miedema BW, Kelly KA. The Roux stasis syndrome. Treatment by pacing and prevention by use of an "uncut" Roux limb. Arch Surg. 1992;127(3):295-300.

6. Shen TF, Chen WC, Han B. Application value of uncut Roux-en-Y anastomosis after radical total gastrectomy. China Journal of Modern Medicine. 2017; 27(6):101-105

7. He TZ Hu Q Zhang L Sun YS Effects of two different reconstruction methods of digestive tract after radical total gastrectomy on quality of life and immune nutrition status in patients with gastric cancer. Chinese Journal of Clinical Nutrition. 2019; 27(3):167-172. 
8. Shi L Chen P Zhao W Liu XX, Wang L, Jiang J, et al Application of uncut Roux-en-Y-esopbagojejunostomy in the digestive tract reconstruction after laperoscopy total gastrectomy[J]. Chin J Curr Adv Gen Surg, 2013, 16(12): 939-946.

9. Zhao TT Bao CQ Xu BH, Shen XM, Yang ZH Effects of Un-cut Roux-en-Y Anastomosis in Laparoscopic Radical Total Gastrectomy for Gastric Cancer. Chin J Min Inv Surg. 2018; 18(12):1095-98.

10. Ye ZY, Sun YS, Shi D, Shao QS, Xu J. Clinical study on the alimentary canal reconstruction of uncutted Roux-en-Y with jejunal pouch for total gastrectomy. Chin J Gastrointest Surg. 2018; 11(5):424-27.

11. Japanese gastric cancer association. Japanese gastric cancer treatment guidelines 2010 (ver. 3). Gastric Cancer 14, 113-123 (2011).

12. Liu J, Yang K, Chen XZ, Dai B, Zhang B, Chen ZX, et al. Quality of life following laparoscopic-assisted distal gastrectomy for gastric cancer. Hepatogastroenterology. 2012; 59(119): 2207-12.

13. Fayers, P. M. et al. On behalf of the EORTC Quality of Life Group. The EORTC QLQ-C30 Scoring Manual (3rd Edition). European Organization for Research and Treatment of Cancer; Brussels, (2001).

14. Vickery CW, Blazeby JM, Conroy T, Arraras J, Sezer O, Koller M, et al. Development of an EORTC disease-specific quality of life module for use in patients with gastric cancer. Eur J Cancer. 2001;37(8):966-71.

15. Huang $Y$ Wang S Shi Y Tang D, Wang W, Chong Y, et al Uncut Roux-en-Y reconstruction after distal gastrectomy for gastric cancer Expert Rev Gastroenterol Hepatol.2016; 10(12):1341-1347

16. Tu BN, Sarr MG, Kelly KA. Early clinical results with the uncut Roux reconstruction after gastrectomy: limitations of the stapling technique. Am J Surg. 1995;170(3):262-4.

17. Uyama I, Sakurai Y Komori Y, Nakamura Y, Syoji M, Tonomura S, et al. Laparoscopy-assisted uncut Roux-en-Y operation after distal gastrectomy for gastric cancer. Gastric Cancer. 2005; 8(4):253-7.

18. Zhu guangxu, Zhou Shengjie, Qu Jianjun.Prevention of closure point recanalization after uncut Roux-en-Y anastomosis for radical resection of distal gastric cancer.Chin J Gastrointest Surg.2020;23(7):717-19.

19. Wang XL, Ma RY, Yin JX, Gao QD, Zhang Z. Feasibility study of uncut Roux-en-Y analysis in totally laparoscopic radical total gastrectomy and reconstruction of disgestive tract. Chin J Oper Proc Gen Surg (Electronic Edition). 2020;14(2):178-81.

20. Shen QY, Yang CS, Wang JS, Lin MB, Cai SX, Li WH, et al. Application of intracorporeal uncut Roux-en-Y anastomosis in digestive tract reconstruction after laparoscopic total gastrectomy. Chin J Gastrointest Surg. 2019; 22(1):43-48.

21. Yun SC Choi HJ Park JY, Kim YJ. Total laparoscopic uncut Roux-en-Y gastrojejunostomy after distal gastrectomy. Am Surg. 2014; 80 (2): E51-3.

22. Aaronson NK, Ahmedzai S, Bergman B, Bullinger M, Cull A, DUez NJ, et al. The European Organization for Research and Treatment of Cancer QLQ-C30: a quality-of-life instrument for use in international clinical trials in oncology. J Natl Cancer Inst. 1993;85(5):365-76.

23. Wan C, Meng Q, Yang Z, Tu X, Feng C, Tang X, et al. Validation of the simplified Chinese version of EORTC QLQ-C30 from the measurements of five types of inpatients with cancer. Ann Oncol. 2008; 19(12):2053-60.

24. Huang CC, Lien HH, Sung YC, Liu HT, Chie WC. Quality of life of patients with gastric cancer in Taiwan: validation and clinical application of the Taiwan Chinese version of the EORTC QLQ-C30 and EORTC QLQ-STO22. Psychooncology. 2007;16(10):945-9.

25. Park JY, Kim YJ. Uncut Roux-en-Y Reconstruction after Laparoscopic Distal Gastrectomy Can Be a Favorable Method in Terms of Gastritis, Bile Reflux, and Gastric Residue. J Gastric Cancer. 2014;14(4):229-37.

\section{Figures}
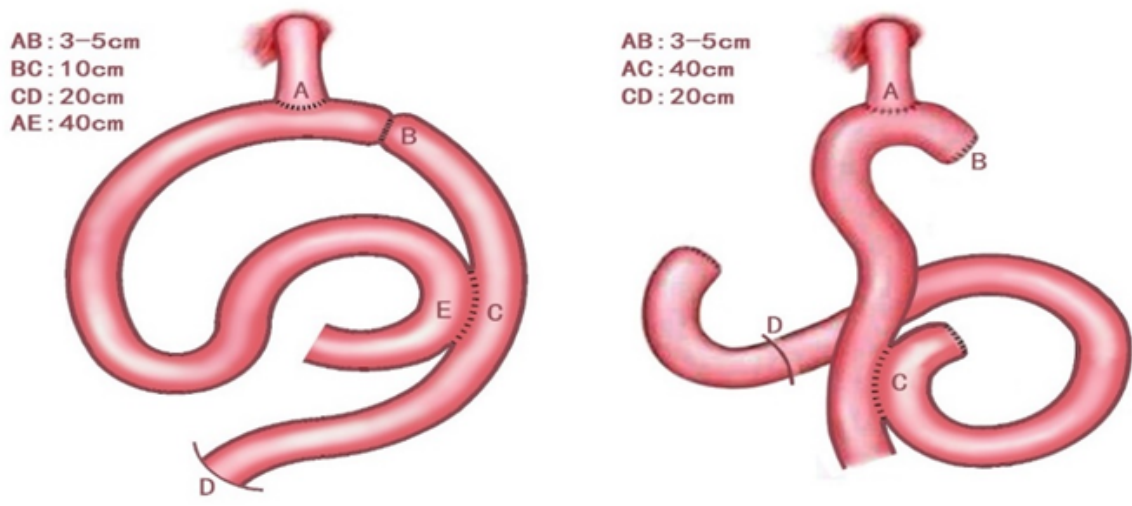

\section{Figure 1}

Uncut Roux-en-Y reconstruction Roux-en-Y reconstruction 


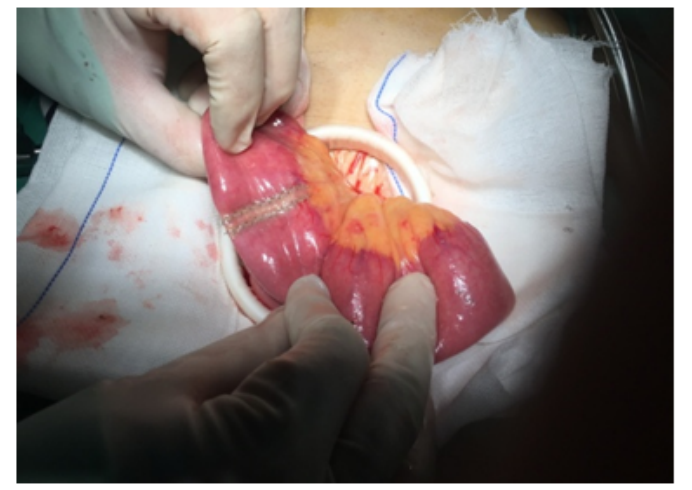

Figure 2

Adopt four-row staplers (knifeless) methods of jejunal occlusion

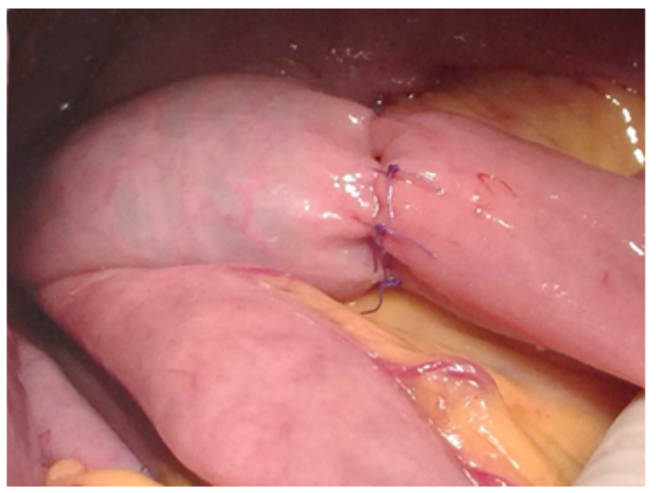

Figure 3

Reinforced by interrupted full-thickness sutures at the occlusion site 

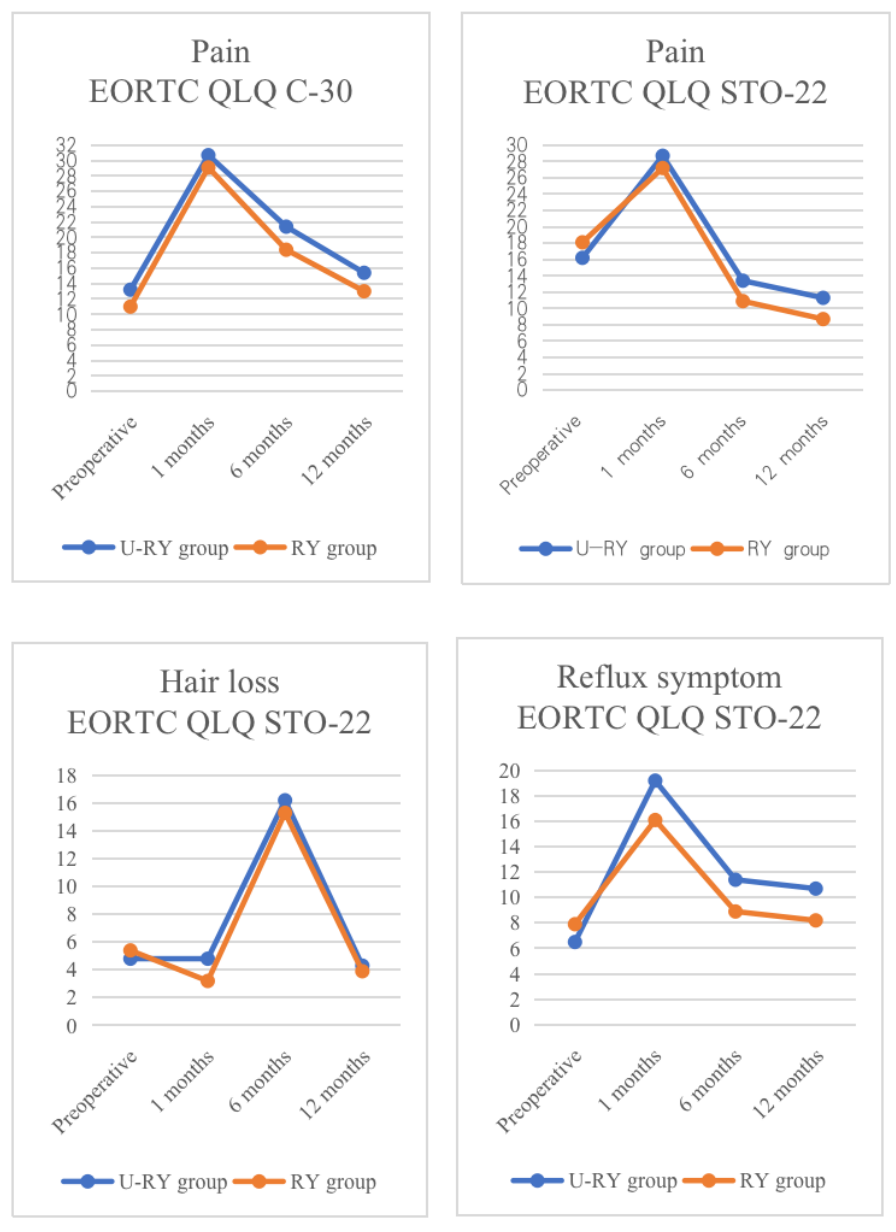

\section{Figure 4}

Comparison of QoL items scores from preoperative baseline to postoperative 12 months between U-RY groups and RY groups.

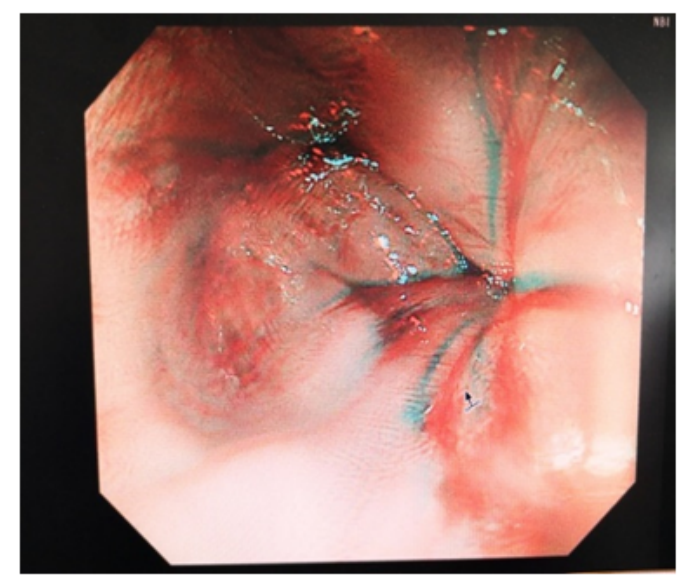

\section{Figure 5}

No recanalization was found at the occlusion site by endoscopy 


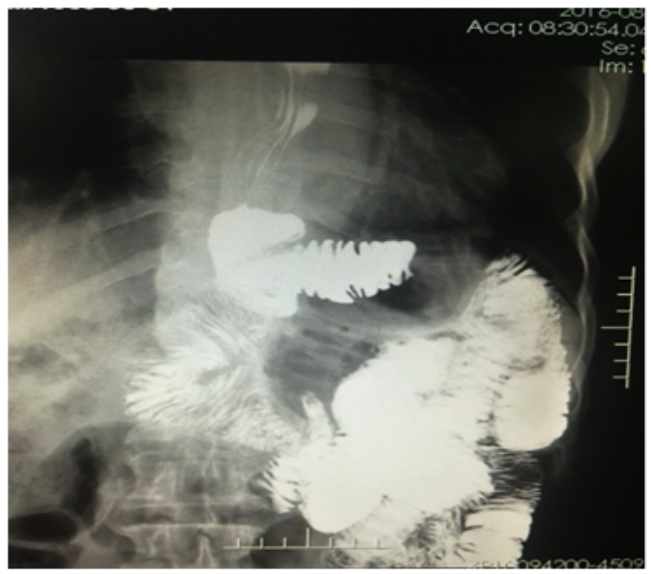

Figure 6

No recanalization was found at the occlusion site by upper gastroenterography 